\title{
Prevalence of Acute Malnutrition and Associated Factors Among Under-Five Children in Gursum District, Somali Region, Ethiopia
}

\author{
Mohamed Arab Abdilahi*, Abdikani Mawlid Nur, Abdireshid Dahir Jibril \\ Department of Public Health, Jigjiga University, Jigjiga, Ethiopia \\ Email address: \\ zakircade3@gmail.com (M. A. Abdilahi), jakemawlid7@gmail.com (A. M. Nur), abdireshid3541@gmail.com (A. D. Jibril) \\ ${ }^{*}$ Corresponding author
}

\section{To cite this article:}

Mohamed Arab Abdilahi, Abdikani Mawlid Nur, Abdireshid Dahir Jibril. Prevalence of Acute Malnutrition and Associated Factors Among Under-Five Children in Gursum District, Somali Region, Ethiopia. Science Journal of Public Health. Vol. 8, No. 4, 2020 , pp. $123-129$. doi: $10.11648 /$ j.sjph.20200804.15

Received: July 23, 2020; Accepted: August 12, 2020; Published: August 25, 2020

\begin{abstract}
Background: Acute malnutrition is one type of under-nutrition that is devastating life and as reflected a nutritionally deficient state of recent onset related to sudden food deprivation or mal-absorption utilization of nutrients which results significant weight loss. In Ethiopia, child under-nutrition is one of the most serious public health problem and the highest in the world. Therefore, this study designed to assess the prevalence of acute malnutrition and its associated factors in children aged 6-59 months in Gursum district in Somali region in Ethiopia. Method: A community-based cross-sectional study was conducted on 541 children aged 6-59 months from Feb. 14-25, 2019. A multistage sampling method was used to select the study participants. Interviewer administered questionnaire was used and EPI-DATA statistical software were entered the data and SPSS version20 were used for analysis. The Z-scores for weight-for-height (WHZ) were calculated using the World Health Organization anthro2010. Binary logistic regression was used to identify the factors associated with acute malnutrition. The statistical significance Variable was declared at P-Value less than0.05. Multi-co-linearity effect was checked. The study found the prevalence of wasting was $21.2 \%(17.54,24.726)$. Educational status of the mother (AOR=1.87, 95\% CL: 1.065, 3.286), diarrhoea two weeks before interview ( $\mathrm{AOR}=2.469,95 \% \mathrm{CI}: 1.487,4.100)$, family size ( $\mathrm{AOR}=1.72,95 \% \mathrm{CL}: 1.058$, 2.797), colostrum feeding (AOR: 2.26; 95\%CI: 1.404, 3.646), bottle feeding (AOR: 3.297; 95\% CI (1.944, 5.591) were significantly associated with acute malnutrition in Gursum district. Conclusion: The prevalence of acute malnutrition in the study area was high. Health extension workers and stakeholders should give concern on promotion of proper nutrition in the community.
\end{abstract}

Keywords: Acute Malnutrition, Under-five Children, Wasting, Jigjiga, Ethiopia

\section{Introduction}

Under-nutrition has persistently remained one of the major public health problems/threats in globally particularly for developing countries $[1,2]$. Acute malnutrition is one type of under-nutrition that is devastating life and as reflected a nutritionally deficient state of recent onset related to sudden food deprivation or mal-absorption utilization of nutrients which results significant weight loss. According to United Nations International Children's Emergency Fund UNICEF]/World Bank estimates, in 2016, nearly 52 million from this 17 million were severely was acute malnutrition [3].
Globally under-nutrition is the major single underlying cause of death in children worldwide [4]. This is responsible approximately 3.1 million deaths in under five children every year which is almost equivalent half [45\%] of all deaths [5]. Moreover, child's under-nutrition is a strong predictor for low school performance, poor mental development as well as greater behavioral problems [6]. Children of acute malnutrition have high probability of death to the counter part from common childhood illness such as diarrhea, pneumonia, and malaria [7]. In Ethiopia, child under- 
nutrition is one of the most serious public health problem and the highest in the world $[8,9]$.

Community based cross sectional study done among Nepal under five children showed that from the total participants $7.0 \%$ were wasted [10]. Multi-analysis study conducted in Nigeria also showed that the prevalence of acute malnutrition was $18 \%$ [11]. The prevalence of acute malnutrition in Ethiopia is among the worst in the world and it remains greatest public health treat. Ethiopian Demographic and Health Survey [EDHS] 2016 reported that $10 \%$ of children were wasted at country level. Somali and Afar region registered the highest prevalence acute malnutrition [wasting] of 23 and $18 \%$, respectively [12]. A Study done In Hawassa, South Nation and Nationalities of Ethiopia showed that wasting was $28.20 \%$ [13]. In Bule Hora district of Oromia region wasting was $13.40 \%$ [14]. The worst figure that showed the prevalence of wasting [42.3\%] was found in Somali region [15]. Although Ethiopia has come a long way in reducing poverty and food insecurity, the prevalent of poverty and food insecurity still present [16]. In Ethiopian's Somali Region, high prevalence of acute malnutrition, food security crisis, Livestock losses and excess mortality among under-five children were reported from the last years [17]. This indicates that acute malnutrition is common problem in Somali region. However, the prevalence of acute malnutrition and associated factors in children aged 6-59 months has not been well documented in the study area. Therefore, this study designed to assess the prevalence of acute malnutrition and its associated factors in children aged 6-59 months in Gursum district in Somali region in Ethiopia. Knowing the extent of the problem and identifying the risk factors related with nutritional status of under-five children in the study area will enable to guide public health planners and policy makers in determining priorities, in designing appropriate and effective nutritional intervention programs to address the problem and its associated consequences

\section{Materials and Methods}

\subsection{Study Area, Design and Period}

Community-based cross-sectional survey was conducted in Gursum district from February14-25, 2019. The district located at a distance of $598 \mathrm{~km}$ from the capital city of Ethiopia.

\subsection{Source of Population and Study Population}

All the children 6 to 59 months of age and their mothers /caregivers (mother - child pair) who were living in Gursum district. Whereas the study population consisted of a sample of All randomly selected children 6 to 59 months of age and their mothers /caregivers (mother - child pair) who were in the selected kebeles in Gursum district Study participants who were living to the study area for 6 months and more were included, children whom others were unable to participate due to illness, and children with physical deformities that hinder height measurements at the time of data collection were excluded from the study.

\subsection{Sample Size and Technique}

The sample size was calculated by using single population proportion formula: $n=Z[\alpha / 2] 2 * p[1-p] / d 2$ by taking the prevalence of wasted children of Similar study conducted in Shinile district in Somali region $(20 \%)$ of wasted children [18]. A multi-stage random sampling technique was used to select the target population. The estimate of the sample in this study was desired to be precise at a confidence level of $95 \%$ and a margin of error of 5\%. Accordingly, 541 children paired with their mothers were selected by considering a $10 \%$ non-respondent rate. The total sample size was distributed among 6 kebeles in the study area according to the number of households in each kebeles. Systematic sampling was used to identify the study households from each Kebele. In cases where household has more than one eligible child to the study in the selected households, a lottery method was used to pick one of them. Moreover, in cases where the selected household was closed or the eligible person was absent two attempts were made to find the respondents.

\subsection{Data Collection Procedures}

Data were collected using structured questionnaire and anthropometric measurement. Eleven data collectors who were able to communicate in Somali were recruited from health centers and health posts in the district. Training was provided for data collectors and supervisor for two days. Anthropometric data: The anthropometric data were collected using the procedure stipulated by the WHO (2006) for taking anthropometric measurements. Before taking anthropometric data for children; the age of the child was taken from growth monitoring and immunization card. For those who missed the card, A local event was used to establish the birth period and age was recorded relying on the date given by the mothers or caretakers.

Dietary diversity score (DDS) was collected as a simple count of 7 food groups consumed by the child in the 24hours prior to the data collection to calculate minimum dietary diversity by using WHO guidance. DDS was calculated by giving a score of (1) for those who consumed $>4$ food items and a score of (0) for those who consume $<4$ food item over the past 24 hours (19). Length/height and weight of each child was measured using standardized and calibrated equipment. Weight was measured with the minimum child wearing clothing (tshirt only) with no shoes using UNICEF Electronic Scale to the nearest of $0.1 \mathrm{~kg}$. The UNICEF mother/child electronic scale requires the mother and child to be weighed at the same time. The mother was weighed with the child and then weighed without the child. The difference between the two measures is the child's weight. The height of infants aged 6-23 months was measured in a recumbent position. Height of children 24 months and older was measured in a standing-up position. The 
measurements were made while the child was in bare-foot and without hair covers and braids affecting the measurement. The recording was measured to the nearest $0.1 \mathrm{~cm}$

\subsection{Statistical Analysis}

The completeness and consistency of the data were checked then data were coded and double entered in to EPI Data 3.1. And exported into SPSS version 20 statistical software for analysis.

Anthropometric data were calculated by using WHO Anthro 2010 software and WHZ score was also been generated based on the WHO child growth standards which was introduced recently in 2006 transported to SPSS. Bivariable logistic regression was used (p-value less than 0.25 ) as candidate to see the association between each independent variable and the outcome variable. Multivariable logistic regression analysis was used to control for all possible confounders and to identify independent predictors of Acute malnutrition. Odds ratio along with $95 \%$ confidence interval were estimated to measure the strength of the association. Level of statistical significance was declared at P-Value less or equal to 0.05 . Multicollinearity effect was checked and variables with $\mathrm{SE}>2$ were removed from analysis. Final model was constructed using enter logistic regression method. All models were checked for their fitness using Hosmer and Leme show goodness of fit test.

\subsection{Ethical Considerations}

Ethical clearance was obtained from the College of Health Sciences of Jigjiga University, Research and Ethical Review Committee (RERC). Then, officials at different levels in the study area were communicated through letters from Somali Regional Health Bureau. Letters of permission were obtained from district administrative and health offices. Verbal informed consent was obtained from each participant prior to the interview after explaining the purpose of the study.

\section{Result}

\subsection{Demographic and Socio-economic Conditions}

From the total 541 planned study participants, complete responses were obtained from 529, with a response rate of $97.7 \%$. As described in Table 1, male headed household (HHs) were 505 (95.5\%) and females were 24 (4.5\%). The majority, $517(97.9 \%)$ of the respondents were married. Average family size was 6.32 persons $(\mathrm{SD} \pm 1.7$ ), while $374(70.7 \%)$ of the HHs have more than five family members. About 20.8 percent of the HHs had three children under-five years of age. Majority of the respondents were Somali ethnic group (99\%) and with regard to religious views, $99.6 \%$ were Muslim Christians. Regarding educational status, $87.9 \%$ of the mothers had no formal education. Out of the total study participants
$416(78.6 \%)$ had multiple wives.

Table 1. Socio-demographic characteristics of the respondents from communities of Gursum District, Somali region, 2019.

\begin{tabular}{llll}
\hline $\begin{array}{l}\text { Characteristics } \\
\text { of participant }\end{array}$ & Category & $\begin{array}{l}\text { Frequency } \\
\text { (n=529) }\end{array}$ & Percentage \% \\
\hline Head of the HH & Male & 505 & 95.5 \\
& Female & 24 & 4.5 \\
Maternal age & $15-34$ & 397 & 75.0 \\
& $35-49$ & 132 & 25.0 \\
Marital status & Married & 517 & 97.7 \\
& Divorced/widowed & 12 & 2.3 \\
Religion & Muslim & 524 & 99.0 \\
Mother's level of & Others & 5 & 1.0 \\
education & Normal education & 64 & 12.1 \\
Paternal level of & formal education & 465 & 87.9 \\
education & No formal education & 203 & 61.6 \\
Mother's & House wife & 474 & 38.4 \\
occupation & Worker & 55 & 89.6 \\
Paternal & Farmers & 309 & 58.4 \\
occupation & Non-farmer worker & 220 & 41.6 \\
Decision -making & Individual & 523 & 98.9 \\
& Jointly/common & 6 & 1.1 \\
Polygamous & Yes & 416 & 78.6 \\
No of under-five & No & 113 & 21.4 \\
children in the & $<3$ & 110 & 20.8 \\
HH & < & 419 & 79.2 \\
& Low & 198 & 37.4 \\
Monthly income & Medium & 170 & 31.1 \\
& High & 161 & 30.4 \\
Family size & $<5$ & 155 & 29.3 \\
\hline & $>5$ & 374 & 70.7 \\
\hline
\end{tabular}

\subsection{Maternal Characteristics}

As showed Table 2, the mean age of the mothers was 29.6 years ( $\mathrm{SD} \pm 6.0)$. Majority, $397(75.0 \%)$ of mothers were in the age group of 15-34 years. Almost all, 521 (98.5\%) of mothers did not take extra food during pregnancy or lactation and $110(20.2 \%)$ did not have good health status during their pregnancy. vast majority, $371(70.1 \%)$ of mothers visited health facilities for antenatal care during pregnancy of the child in the present study. (Table 2)

Table 2. Maternal characteristics of the respondents from communities of Gursum District, Somali region, 2019.

\begin{tabular}{llll}
\hline Characteristics & Category & Number & \% \\
\hline \multirow{2}{*}{ How many childrenhave born } & $<4$ & 288 & 54.6 \\
& $>4$ & 241 & 45.4 \\
Extra food during pregnancy & Yes & 8 & 1.5 \\
& No & 521 & 98.5 \\
ANC visit & Yes & 371 & 70.1 \\
& No & 158 & 29.9 \\
Health status of mother & Sick & 110 & 20.2 \\
& Good & 419 & 79.8 \\
\hline
\end{tabular}

\subsection{Child Feeding Practices Characteristics}

Out of the total study subject 529 children aged 6-59 months, two hundred seventy-nine $(52.7 \%)$ were female, and the rest $250(47.3 \%)$ were male in sex. The mean age of children was 29.25 months $(\mathrm{SD} \pm 13.2)$. Among the study 
participants, $518(97.7 \%)$ of children were delivered at home and $11(2.3 \%)$ children were delivered at health facilities. No oedema case was recorded in the study area two weeks prior to or during the data collection period. As indicated in table 3. From the total study participants, breastfeeding practice was initiated immediately after birth for 437 (82.6\%) children. $378(71.5 \%)$ children had received pre-lactation food or fluids. And about 365 (69\%) children didn't receive colostrum's at birth. Most of the children, 437 (80.7\%) children were exclusively breastfeed until six months of age (Table 3).

Table 3. Child feeding practices characteristics of the respondents from communities of Gursum District, Somali region, 2019.

\begin{tabular}{|c|c|c|c|}
\hline \multirow{2}{*}{ Characteristics } & \multirow{2}{*}{ Category } & \multicolumn{2}{|c|}{ Frequency } \\
\hline & & $\mathbf{N}$ & $\%$ \\
\hline \multirow{2}{*}{ Breast feeding ever } & Yes & 529 & 100 \\
\hline & No & 0 & 0.0 \\
\hline \multirow{3}{*}{$\begin{array}{l}\text { Initiation of breast feeding of } \\
\text { the child }\end{array}$} & Immediate & 437 & 82.6 \\
\hline & After 1 to $24 \mathrm{hrs}$ & 51 & 9.6 \\
\hline & After days & 41 & 7.8 \\
\hline \multirow{2}{*}{ Frequency of BF } & $>8$ times & 382 & 72.2 \\
\hline & $<8$ times & 147 & 27.8 \\
\hline \multirow{2}{*}{ Colostrum feeding } & Yes & 164 & 31.0 \\
\hline & No & 365 & 69.0 \\
\hline \multirow{2}{*}{ Duration of breast feeding } & $>12$ months & 313 & 52.7 \\
\hline & $<12$ months & 216 & 47.3 \\
\hline \multirow{2}{*}{ Pre-lacteal feed } & Yes & 378 & 71.5 \\
\hline & No & 151 & 28.5 \\
\hline \multirow{3}{*}{ Type of pre-lactation } & Water & 381 & 100 \\
\hline & Other milk, butter & 0 & 0.00 \\
\hline & $<6->8$ months & 341 & 64.5 \\
\hline Initiation of $\mathrm{CF}$ & 6-8 months & 188 & 35.5 \\
\hline \multirow{2}{*}{ Frequency of $\mathrm{CF}$ feeding } & $<3$ times & 160 & 30.2 \\
\hline & $>3$ times & 369 & 69.8 \\
\hline \multirow{2}{*}{ Method of feeding } & Bottle feeding & 278 & 52.6 \\
\hline & Others & 251 & 47.4 \\
\hline \multirow{2}{*}{ Had child separate feed plate } & Yes & 15 & 2.8 \\
\hline & No & 514 & 97.2 \\
\hline \multirow{2}{*}{$\begin{array}{l}\text { MDD } 24 \text { hours before the } \\
\text { survey }\end{array}$} & $<4$ food items & 370 & 69.9 \\
\hline & $\geq 4$ food items & 159 & 30.1 \\
\hline \multirow{3}{*}{ Child's age } & $6-23$ & 194 & 36.7 \\
\hline & $24-35$ & 148 & 28.0 \\
\hline & $36-59$ & 187 & 35.3 \\
\hline \multirow{2}{*}{ Child's sex } & Female & 279 & 52.7 \\
\hline & Male & 250 & 47.3 \\
\hline \multirow{2}{*}{ Relationship with the child } & Mother & 479 & 90.5 \\
\hline & Caregiver & 50 & 9.5 \\
\hline \multirow{2}{*}{ Birth interval } & $>2$ years & 294 & 55.4 \\
\hline & $<2$ years & 235 & 44.6 \\
\hline \multirow{2}{*}{ Place of delivery } & Home & 518 & 97.9 \\
\hline & health facility & 11 & 2.1 \\
\hline \multirow{2}{*}{ Took vaccination } & Yes & 517 & 97.7 \\
\hline & No & 12 & 2.3 \\
\hline \multirow{2}{*}{ Vaccination card availability } & Yes & 506 & 97.9 \\
\hline & No & 11 & 2.1 \\
\hline \multirow{2}{*}{ Diarrheal status of child } & Yes & 110 & 20.8 \\
\hline & No & 419 & 79.2 \\
\hline \multirow{2}{*}{ Fever status of child } & Yes & 416 & 78.6 \\
\hline & No & 113 & 21.4 \\
\hline
\end{tabular}

\subsection{Environmental Health Characteristics of Households}

Almost half and above of the main sources of drinking water used by households, 277 (52.6\%) were unprotected water. from the total of $283(53.5 \%)$ of households require greater than 30 minutes fetching water from these sources. With regarding to treating drinking water in households, majority of $\mathrm{HHs}$ (517) $97.7 \%$ were not treat water. Concerning about toilet facilities, Majority of households 364 $(68.8 \%)$ had no latrine. In this study district, wooden slap of latrine is the most commonly being utilized and almost all households were wash hand after toilet. Regarding waste disposal system, 210 (39.7\%) and 319 (60.3\%) households were dispose garbage in a pit and open field, respectively. (table 4)

Table 4. Environmental health characteristics of the respondents from communities of Gursum District, Somali region, 2019.

\begin{tabular}{|c|c|c|c|}
\hline \multirow{3}{*}{$\begin{array}{l}\text { Characteristics } \\
\text { Drinking water }\end{array}$} & \multirow{2}{*}{$\begin{array}{l}\text { Category } \\
\text { protected water }\end{array}$} & \multicolumn{2}{|c|}{ Number \% } \\
\hline & & 252 & 47.4 \\
\hline & Unprotected water & 277 & 52.6 \\
\hline \multirow{2}{*}{ Time to obtain drinking water } & $>30$ minutes & 283 & 53.5 \\
\hline & $<30$ minutes & 246 & 46.5 \\
\hline \multirow{2}{*}{ Utilization of treated water } & Yes & 12 & 2.3 \\
\hline & No & 517 & 97.7 \\
\hline \multirow{2}{*}{ Availability of latrine } & Yes & 165 & 31.2 \\
\hline & No & 364 & 68.8 \\
\hline \multirow{2}{*}{$\begin{array}{l}\text { washing hands before and after } \\
\text { feeding }\end{array}$} & Yes & 529 & 100 \\
\hline & No & 0 & 0.00 \\
\hline \multirow{2}{*}{ Material used hand washing } & Water only & 521 & 98.5 \\
\hline & Water with soap & 8 & 1.5 \\
\hline \multirow{2}{*}{$\begin{array}{l}\text { Having proper waste disposal } \\
\text { management (observation) }\end{array}$} & Yes & 210 & 39.7 \\
\hline & No & 319 & 60.3 \\
\hline
\end{tabular}

\subsection{Nutritional Status of the Children}

Prevalence of acute malnutrition among children aged 659 months in the study area were $21.2 \%$. Acute malnutrition was higher among female under-five children compared to males.

\subsection{Factors Associated with Wasting}

As indicated below, the bi-variate analysis showed that family size, maternal education, status of polygamy, colostrum feeding, method of feeding, pre-lacteal feeding child sex, diarrheal status, birth interval and waste disposal management were significantly associated with wasting (Table 5).

Based on the multivariate regression analysis of this study revealed that children whose mother no formal education were 1.87 times more risk to have acute malnutrition as compared to children whose mothers had formal education $(\mathrm{AOR}=1.870(1.065,3.286)$. Children who had diarrhoea two weeks before interview were 2.4 times risk of acute malnutrition as compared to children had not diarrhoea (AOR $=2.469 ; 95 \%$ CI: 1.487, 4.100). Also this study indicated that children who had not fed colostrum were 2.26 times more likely to be wasted as compared to children who were receiving colostrum feeding (AOR: 2.26; 95\%CI: 1.404 , 3.646). children from family size more than 5 were 1.72 times more risk to have acute malnutrition as compared to children from family size less than five $(\mathrm{AOR}=1.720$ (1.058, 
2.797). Also, this study indicated that children who were bottle feeding were more like to develop acute malnutrition compared to the children who were feed cup or teaspoon (AOR: 3.297; 95\%CI: 1.944, 5.591).

Table 5. Factors associated of wasting among under five children in Gursum district, Somali Region. 2019 ( $n=529)$.

\begin{tabular}{|c|c|c|c|c|c|}
\hline \multirow{2}{*}{ Variable } & \multirow{2}{*}{ Category } & \multicolumn{2}{|l|}{ Wasting } & \multirow{2}{*}{ COR (95\% CI) } & \multirow{2}{*}{$\operatorname{AOR}(95 \%$ CI) } \\
\hline & & Stunted \%) & Normal (\%) & & \\
\hline \multirow{2}{*}{ Family size } & $<5 \mathrm{yrs}$ & $45(27.4)$ & $119(72.6)$ & 1.00 & 1.00 \\
\hline & $>5 \mathrm{yrs}$ & $67(18.4)$ & $298(81.6)$ & $1.682(1.090,2.594)$ & $1.720(1.058,2.797) * *$ \\
\hline \multirow{2}{*}{ Maternal education } & Formal education & $32(34.0)$ & $62(66.0)$ & 1.00 & 1.00 \\
\hline & Non-formal education & $80(18.4)$ & $355(81.6)$ & $2.290(1.402,3.741)$ & $1.870(1.065,3.286) * *$ \\
\hline \multirow{2}{*}{ Polygamy } & Yes & $85(24)$ & $331(79.6)$ & $1.223(0.746,2.003)$ & $1.207(0.699,2.086)$ \\
\hline & No & $27(23.9)$ & $86(76.1)$ & 1.00 & 1.00 \\
\hline \multirow{2}{*}{ Colostrum feeding } & Yes & $52(31.7)$ & $112(68.3)$ & 1.00 & 1.00 \\
\hline & No & $60(16.4)$ & $305(83.6)$ & $2.360(1.538,3.628)$ & $2.263(1.404,3.646) * *$ \\
\hline \multirow{2}{*}{ Pre-lacteal feeding } & Yes & $89(23.5)$ & $289(76.5)$ & $1.714(1.036,2.836)$ & $0.575(0.322,1.027)$ \\
\hline & No & $23(15.2)$ & $128(84.8)$ & 1.00 & 1.00 \\
\hline \multirow{2}{*}{ Method of feeding } & Bottle feeding & $24(10.9)$ & $197(89.1)$ & $3.283(2.010,5.363)$ & $3.297(1.944,5.591) * *$ \\
\hline & Not B/feeding & $88(28.6)$ & $220(71.4)$ & 1.00 & 1.00 \\
\hline Child's sex & Female & $74(24.9)$ & $223(75.1)$ & 1.00 & 1.00 \\
\hline \multirow{2}{*}{ Diarrhoea } & Yes & $71(17.4)$ & $336(82.6)$ & $2.395(1.520,3.774)$ & $2.469(1.487,4.100) * *$ \\
\hline & No & $41(33.6)$ & $81(66.4)$ & 1.00 & 1.00 \\
\hline \multirow{2}{*}{ Birth interval } & $>=2 \mathrm{yrs}$ & $70(24.8)$ & $212(75.2)$ & 1.00 & 1.00 \\
\hline & $<2 \mathrm{yrs}$ & $42(17.0)$ & $205(83.0)$ & $1.612(1.060,2.473)$ & $1.432(0.884,2.319)$ \\
\hline \multirow{2}{*}{$\begin{array}{l}\text { Waste disposal } \\
\text { management }\end{array}$} & Yes & $35(16.7)$ & $175(83.3)$ & 1.00 & 1.00 \\
\hline & No & $77(24.1)$ & $242(75.9$ & $1.591(1.020,2.481)$ & $1.571(0.947,2.606)$ \\
\hline
\end{tabular}

$\mathrm{AOR}=$ Adjusted Odd Ratio; $\mathrm{CI}=$ Confidence Interval, $\mathrm{COR}=$ Crude Odd Ratio; $*=\mathrm{p}$-value $<0.05$.

\section{Discussion}

The prevalence of acute malnutrition was high $21.2 \%$ $(17.54,24.726)$ in the district. This study noted that family size, maternal education, colostrum feeding, method of feeding and diarrheal status was statistically significant associated for acute malnutrition.

This study showed that the prevalence of acute malnutrition was higher compared to others studies done different corner Ethiopia [20-23] The differences in the prevalence of malnutrition among children could be attributed to the difference in the method of data collection, sample size, study subjects or may be due to socioeconomic and seasonal variation as compared with the present study. The prevalence of acute malnutrition is relatively higher than the national figure while almost similar with the regional figure and study done Somali region and study done in India $[24,25]$.

Even though the prevalence of acute malnutrition in this study was high, it was lower as compared to studies conducted in Kilimanjaro Region, Tanzania [26] Ethiopia in Dolo-Ado Somali region [15]. Hawassa South Ethiopia [13], Mai-Aini Eritrean Refugees' Camp, Northern Ethiopia [27].

In this study, maternal educational status was significantly associated with acute malnutrition. Children whose mothers had no formal education were 1.8 times at risk to have acute malnutrition as compared to those children have literate mothers. This was in line with studies done in Afghanistan [28], in Nigeria [29]. Similar findings revealed that maternal education has negative relationship to acute malnutrition [30]
Gedeo Zone, Ethiopia [31] Libokemkem district, Amhara region [32] Study done Shashogo Woreda, Southern Ethiopia [33], Hawassa Zuria District, Southern Ethiopia [34], Somali Region, Ethiopia [15], study done Ethiopia [22] Bula hora district, Ethiopia [14] other study done Ethiopia [35] Ethiopia [36]. This could be attributed to the fact that Educated mothers might be more nutritionally literate and might have more knowledge of child feeding practices.

The study also revealed that Presence of diarrhea in the last two weeks was significantly associated with acute malnutrition. In this study, presence of diarrhea increased a risk of acute malnutrition in 2.4-folds as compared when not diarrhea. This was consistent with study done Afghanistan [28]. Also the finding of this study was in line with studies done Ethiopia revealed that diarrhea increases the risk of acute malnutrition almost two to five times more likely than those who had not diarrhea $[20,21,30,33,37,38]$. This may be attributed to vicious cycle relationship between infectious diseases and nutritional status. Presence of diarrhea and fever causes loss of appetite and decreased intake of food which intern leads to weight loss and the children quickly become undernourished. On the other hand undernourished status further leads to the occurrence of diarrhea and other infectious diseases due to immune decline.

This study also indicated that, there was significant association between lack of colostrum feeding and wasting. The odds of wasting were 2.26 times higher children who had not fed colostrum than those had fed colostrum. This was consistent with study done in India [39]. Also, study done Ethiopia [40]. This is probably colostrum provides protective effect to the newborn and infants because colostrum is highly 
nutritious and has antibodies that protect the newborn from communicable diseases [25]. Therefore, colostrum avoidance results simple introduction of infection in the first years of child's life and makes vulnerable to under-nutrition.

In the study area. Bottle feeding was a significantly determinant for acute malnutrition in this study, which was consistent with the findings of studies done in Nepal [41] India [42] Ethiopia [35] The reason might be poor hygiene associated with the bottle or inappropriate preparation of the formula, leading to diarrhea and other diseases.

Furthermore, this study showed that family with more than four members is significantly associated with acute malnutrition. Children from family size more than four were 1.7 times at risk to have acute malnutrition as compared to children from family size less than four. A study conducted in Pakistan [43]. Systematic review conducted in Ethiopia showed that large family size in the household have statistical significant to acute malnutrition [30] Gedeo zone, Ethiopia [31] Study done Ethiopia [22] Afar region, Ethiopia [21] Ethiopia [35]. Study done Somali region, Ethiopia [44]. This could be increased number of family size placed a heavy burden on the scarce household resources, particularly on financial and food; it also reduced the time and quality of care received by the children.

\section{Conclusion and Recommendations}

The result of this study found that acute malnutrition was highly prevalent that confirms the nutritional condition in the study area is serious. The figure of wasting in the study area was higher than 2016 EDHS national. This study found that among the risk factors; maternal formal education status, diarrhea, colostrum feeding, method of feeding and family size becomes the main risk factors that contribute for the occurrence acute malnutrition of children in the study area. Thus, to tackle these problem efforts should be made to improve maternal education and to create awareness IYCF to develop behavior change communication for better child feeding and caring practices in the to prevent and control childhood illness.

\section{References}

[1] Rabbi AMF, SC. K. Determinants of child malnutrition in Bangladesh -a multivariate approach. Asian J Med Sci 2014; 6 (2): 85-90.

[2] de Onis M, Frongillo EA, Blossner M. Is malnutrition declining? An analysis of changes in levels of child malnutrition since 1980. Bulletin of the World Health Organization. 2000; 78 (10): 1222-33.

[3] UNICEF, WHO, Bank: W. levels and trends in child malnutrition; UNICEF /WHO / World Bank Group joint child malnutrition estimates: key findings ofthe 2017 edition. 2017; 017.pdf.

[4] WHO. Children: reducing mortality. From; www.who.intoutgrowthpublications/health-quantifying. retrieved on July 8/2015 retrieved on July 4/2015. 2009: 178 .

[5] Black RE, Victora CG, Walker SP, Bhutta ZA, Christian P, de Onis $\mathrm{M}$, et al. Maternal and child undernutrition and overweight in low-income and middle-income countries. lancet. 2013: 427-51.

[6] Martins VTB, Florencio TMMT, Grillo LP, Franco MP, Martins PA, Clemente APG, et al. Long lasting effects of under nutrition. 2011. Int J Environ Res Public Health 2011; 8 (6): 1817-46.

[7] WHO. Children: reducing mortality. 2019.

[8] Alemu M, Nicola J, Bekele T. Tackling Child Malnutrition in Ethiopia: Do the Sustainable Development Poverty Reduction Programme's underlying policy assumptions reflect local realities? young lives. 2005: No. 19.

[9] Solomon A, Tigabu Z. Risk factors for severe acute malnutrition in children under the age of five: A casecontrol study. EthiopJHealth Dev. 2008.

[10] Chataut J, K. K. Assessment of nutritional status of children under five years of age in rural Nepal. Kathmandu Univ Med J 2016; 53 (1): 73-7.

[11] Blessing J. A., Kingsley E. A., M. D, H. JJ, R. AM. Multilevel Analysis of Factors Associated with Wasting and Underweight among Children Under-Five Years in Nigeria. Nutrients 2017; 9: 44.

[12] ICF: CSA-CE. Ethiopia demographic and health sruvey. Addis Ababa: CSA and ICF; 2017. 2016.

[13] Tsedeke W, Tefera B, B. T. Prevalenc of undernutrition and determinant factors among preschool children in Hawassa, Southern Ethiopia. Food Sci Qual Manag. 2014: 29.

[14] M. Asfaw, M. Wondaferash, M. Taha, and L. Dube. Prevalence of under nutrition and associated factors among children aged between six to fifty nine months in Bule Hora district, South Ethiopia. " BMC Public Health. 2015; vol. 15, n (no. 1,): p. 41, 2015.

[15] Demissie S, and A. Worku. Magnitude and Factors Associated with Malnutrition in Children 6-59 Months of Age in Pastoral Community of Dollo Ado District, Somali Region, Ethiopia. Science Journal of Public Health 2013; 1, (4): 175-83.

[16] CSA ECSA, WFP. WFP. Ethiopia comprehensive Food Security and Vulnerability Analysis. (CFSVA). 2014.

[17] Famine Early Warninig Network. ETHIOPIA Food Security Alert Severe food insecurity in Somali Region likely to deteriorate further given lack of food aid. 2017.

[18] ABDIBARI M, DEREJE, B., SAMUEL, M., DANIEL, T., YUSUF, M. \& GEBREMICHEAL., K. 2016. Magnitude and factors associated with malnutrition in children 6-59 months of age in Shinille Woreda, Ethiopian Somali regional state: a cross-sectional study. BMC Nutrition 2 (1) 44 https://doi.org/10.1186/s40795-016-0079-1. 2, 44.

[19] WHO. Indicators for assessing infant and young child feeding practices Part 2 Measurement. 2010.

[20] L. Abera, D. Tariku, L. Tariku. Prevalence of malnutrition and associated factors in children aged 6-59 months among rural dwellers of damot gale district, south Ethiopia: community based cross sectional study. International Journal for Equity in Health. 2017: 16: 111. 
[21] A. Gebre, P. Surender Reddy, A. Mulugeta, Y. Sedik, Kahssay M. Prevalence of Malnutrition and Associated Factors among Under-Five Children in Pastoral Communities of Afar Regional State, Northeast Ethiopia: A Community-Based Cross-Sectional Study. Hindawi Journal of Nutrition and Metabolism. 2019; Volume 2019, 13 pages.

[22] A. K. Tekile, A. A. Woya, Basha GW. Prevalence of malnutrition and associated factors among under-fve children in Ethiopia: evidence from the 2016 Ethiopia Demographicand Health Survey. BMC. 2019; 12: 391.

[23] Taye A, Wolde T, A S. Under-nutrition and Related Factors among Children Aged 6-59 Months in Gida Ayana District, Oromiya Region, West Ethiopia: A Community Based Quantitative Study. J Nutr Food Sci 2016; 6: 543.

[24] Ghosh S, SA. V. Undernutrition among tribal children in Palghar district, Maharashtra, India. PLoS ONE (2019); 14 (2): e0212560.

[25] CSA. Ethiopia Demographic and Health Survey Addis Ababa, Ethiopia.

From; https://dhsprogram.com/pubs/pdf/FR328/FR328.pdf retrieved on October /9/2017. 2016.

[26] M. Mgongo, N. A. S. Chotta, T. H. Hashim, J. G. Uriyo, D. J. Damian, B. S. Pedersen, et al. Underweight, Stunting and Wasting among Children in Kilimanjaro Region, Tanzania; a Population-Based Cross-Sectional Study. Int J Environ Res Public Health 2017; 14: 509.

[27] Kelati H, Mengiste B, Alemayehu T, and Damtew B. "Prevalence of acute malnutrition and its associated factors among children aged 6-59 months in Mai-Aini Eritrean refugees' camp, Northern Ethiopia," International Journal of Food Sciences and Nutrition, v. 2015; ol. 5, (no. 1): p. 336.

[28] M. Kamel Frozanfar, Y. Yoshida, E. Yamamoto, J. Reyer, S. Dalil, A. Darman Rahimzad, et al. Acute malnutrition among under-five children in Faryab, Afghanistan: prevalence and causes. Nagoya J Med Sci 2016; 78: 41-53.

[29] Babatunde RO. Prevalence and Determinants of Malnutrition among Under-five Children of Farming Households in Kwara State, Nigeria. Journal of Agricultural Science. 2011.

[30] A. Abdulahi, Sh. Rezaei, K. Djafarian, Shabbidar. S. Nutritional Status of Under Five Children in Ethiopia: A Systematic Review and Meta-Analysis. Ethiop J Health Sci 2017. 2017; 27 (1): 175. DOI: 10.4314/ejhs.v27i2.10.

[31] Abuka T, Jembere D, D. T. Determinants for Acute Malnutrition among Under-Five Children at Public Health Facilities in Gedeo Zone, Ethiopia: A Case-Control Study. Pediatr Ther 2017; 7: 317 .

[32] A. Motbainor, A. Taye. Wasting in under five children is significantly varied between rice producing and nonproducing households of Libokemkem district, Amhara region, Ethiopia. BMC Pediatrics· 2019; 19: 300.
[33] N D. Determinants of Severe Acute Malnutrition among Under Five Children in Shashogo Woreda, Southern Ethiopia: A Community Based Matched Case Control Study. J Nutr Food Sci. (2014) 4: 300.

[34] D. Danbe Debeko, Goshu. AT. Nutritional Status of Underfive Children in Hawassa Zuria District, Southern Ethiopia. American Journal of Health Research 2015; Vol. 3, (No. 5,): pp. 286-92.

[35] Amsalu S. TZ. Risk factors for ever acute malnutrition in children under the age of five: a case-control study. Ethiopian Journal of Health Development 2. 2008; 22: 21-5.

[36] Endris N, Asefa H, Dube L. Prevalence of Malnutrition and Associated Factors among Children in Rural Ethiopia. Biomed Res Int. 2017; 6587853.

[37] Awoke A, Ayana M, Gualu T. Determinants of severe acute malnutrition among under five children in rural Enebsie Sarmidr District, East Gojjam Zone, North West Ethiopia. Awoke et al BMC Nutrition 2018; 4 (5): 4.

[38] B. T. Woldeamanue, T. Tesfaye. T. Risk Factors Associated with Under-Five Stunting, Wasting, and Underweight Based on Ethiopian Demographic Health Survey Datasets in Tigray Region, Ethiopia. Hindawi Journal of Nutrition and Metabolism. 2019; Volume 2019, 11 pages.

[39] Ambadekar N, Zodpey S. Risk factors for severe acute malnutrition in under-five children: a case-control study in a rural part of India. ELSEVIER. 2017; 142: 136-43.

[40] Darsene H, Geleto A, Gebeyehu A, Meseret S. Magnitude and predictors of undernutrition among children aged six to fifty nine months in Ethiopia: a cross sectional study. Archives of Public Health. 2017; 75 (1): 29.

[41] Pravana NK, Piryani S, Chaurasiya SP, Kawan R, Thapa RK, Shrestha S. Determinants of severe acute malnutrition among children under 5 years of age in Nepal: a community-based case-control study. BMJ Open. 2017; 7 (8): e017084-e.

[42] Mishra K, Kumar P, Basu S, Rai K, Aneja S. Risk Factors for Severe Acute Malnutrition in Children below $5 \mathrm{y}$ of Age in India: A Case-Control Study. The Indian Journal of Pediatrics. 2014; 81 (8): 762-5.

[43] Nisar MU, Anwar Ul Haq MM, Tariq S, Anwar M, Khawar A, Waqas A, et al. Feeding Patterns and Predictors of Malnutrition in Infants from Poor Socioeconomic Areas in Pakistan: A Cross-sectional Survey. Cureus. 2016; 8 (1): e452e.

[44] A. Ma'alin, D. Birhanu, S. Melaku, D. Tolossa, Y. Mohammed, and K. Gebremicheal. "Magnitude and factors associated with malnutrition in children 6-59 months of age in Shinille Woreda, Ethiopian Somali regional state: a cross-sectional study”. BMC Nutrition, 2016; vol. 2, (no. 1,): p. 44. 